\title{
The Association of Factor V Leiden Mutation With Recurrent Pregnancy Loss Using Activated Protein C Resistance Test : Case Control Study
}

\section{Original Article}

\author{
Ahmed M. Hussien', Abdel Mageed I. Abdel Mageed', Manal F. Gabr', Raghda A. \\ Abouelela $^{1}$
}

${ }^{1}$ Department of Obstetrics and Gynecology, ${ }^{2}$ Department of Clinical Pathology, Faculty of Medicine, Ain-Shams University, Egypt

\begin{abstract}
Background: Recurrent pregnancy loss is considered as a major devastating obstetric and gynecological health problem. Many clinicians define RPL as three or more consecutive pregnancies ending spontaneously before the $20^{\text {th }}$ week of gestation. Aim: This work aimed to investigate the prevalence of FVL mutation in women with RPL using a less time and money consuming test, APCR test.

Materials and Methods: This study compared the prevalence of FVL among 83 patients with history of 3 or more first trimester pregnancy losses (the case group) with an equal number of women with no history of RPL (the control group), recruited from the RPL outpatient clinic at the Obstetrics and Gynecology Department of Ain-Shams University Maternity Hospital, during the period between April 2018 till June 2019.

Results: Abnormal APCR test values were found in a total of 22 women in this study, 7 women in the control group $(8.4 \%)$ and 15 in the case group (18.07\%) with no statistically significant differences. However, in further assessment of case group, two patients in the case group with abnormal APC value, suffered from DVT episodes, representing $13.3 \%$ of 15 patients with abnormal APCR. The P value was statistically significant, which mean that the present of APCR might increase the risk for DVT.

Conclusion: Isolated FVL is unlikely to be an important cause for RPL as no statistically significant difference is found between the case and control groups.
\end{abstract}

Key Words: Factor V Leiden mutation, protein C resistance, recurrent pregnancy loss

Received: 22 November 2019, Accepted: 21 March 2020

Corresponding Author: Raghda Ayman Abouelela, Department of Obstetrics and Gynecology, Faculty of Medicine, Ain-Shams University, Egypt, Tel.: 01006661386, E-mail: raghda.abouelela@gmail.com

ISSN: 2090-7265, February 2021, Vol.11, No. 1

\section{INTRODUCTION}

Recurrent pregnancy loss (RPL) is a traumatic event, which may lead to symptoms of depression, anxiety, lowered self-esteem and other psychosocial consequences $^{[1]}$.

Many clinicians define RPL as three or more consecutive pregnancies ending spontaneously before the $20^{\text {th }}$ week of gestation. However, more than two pregnancy losses, including those which are not consecutive, are also recently considered as recurrent spontaneous abortions. It is an important reproductive health issue affecting $2 \%-5 \%$ of couples ${ }^{[2]}$.

One of the pathophysiological pathways of interest is based on the observed association between recurrent miscarriage and thrombophilia.

Thrombophilia refers to any persistent identifiable hypercoagulable state either acquired or inherited associated with an increased risk of both venous and arterial thromboembolism. The most important form of acquired thrombophilia is APAS which has well established role in the incidence of RPL ${ }^{[3]}$.

Inherited thrombophilias include a group of mostly autosomal dominant, inherited gene mutations leading to hypercoagulable state, including antithrombin III (ATIII) deficiency, protein $\mathrm{C}$ and protein $\mathrm{S}$ deficiencies, and mutations in the genes encoding clotting factors as Prothrombin gene mutation (G20210A), Factor V Leiden (FVL) and others. They are one of the most important predisposing factors for venous thromboembolism (VTE) in pregnancy and many studies suggested their role in many adverse pregnancy outcomes as RPL ${ }^{[4]}$.

FVLis the most common known inherited thrombophilia. It is an autosomal dominant genetic condition, which occurs as a result of a single point mutation in the factor $\mathrm{V}$ gene. This mutation results in a replacement of 
Arginine (R) 506 with Glutamine (Q) in one of the factor $\mathrm{V}$ cleavage sites for Activated Protein C (APC) (Arg 506) where APC acts ${ }^{[5]}$.

This substitution leads to a factor $\mathrm{V}$ species that cannot be degraded by APC. The rate of inactivation of FVL by APC is 10-20 fold lower compared to the rate of degradation of normal factor $\mathrm{V}$, explaining the hypercoagulable state and the life-long increase risk of thrombosis ${ }^{[6]}$.

Over the past 3 decades, many studies have suggested the strong association between FVL and many adverse pregnancy outcomes as preeclampsia, IUGR, placental abruption and RPL.

\section{AIM OF THE WORK}

To investigate the role of FVL in Egyptian women with first trimesteric recurrent pregnancy loss and in healthy control women after exclusion of obstetric factors using APC resistance test which is much cheaper than DNAPCR test and see if the results will be in favor of using APC resistance test as a screening method afterward.

\section{PATIENTS AND METHODS}

Study design: This study was designed as cross-sectional case-control.

Study Site: Obstetric Outpatient Clinic, Ain-Shams University Maternity Hospital.

Duration of the study: The study was done during the period between April 2018 and June 2019.

Study population: This study was conducted on a total of 166 women within the reproductive age group, where 83 women with history of RPL represented the cases and 83 women with no history of RPL and with at least one live birth represented the control group.

Inclusion criteria: Both cases and control will give a written consent. Age between 18 to 40 years old. For cases: history of 3 or more $1^{\text {st }}$ trimesteric miscarriage. For control group: no history of RPL and a history of at least one successful delivery must be present. Lupus anti-coagulant, anti-cardiolipin antibodies are negative. Normal complete blood count, prothrombin time, partial prothrombin time, thyroid stimulating hormone, fasting blood sugar and post prandial glucose test results.

Exclusion criteria: Women known to have diabetes, hypertension, thyroid disorders, liver, renal or autoimmune diseases. Smokers. Presence of Uterine anomalies detected by $3 \mathrm{D} \mathrm{U} / \mathrm{S}$.

The following procedures were performed: consent; a written informed consent was taken from each patient. The patient was told that a blood sample would be withdrawn from her. The importance of the test was explained to the patient. If she refused withdrawal of the blood sample, she was excluded from the study.

Personal data: Full history taking focusing on personal history, including name, age, occupation, duration of marriage, habits of medical importance.

Past history: to identify any signs of systemic diseases as diabetes mellitus, hyper and hypo-thyroidism, hypertension. Menstrual history including regularity and duration. Family history including positive consanguinity, history of RPL or recurrent thrombosis in the family. Obstetric history, the history of the previous pregnancies was taken in details. In each pregnancy loss, we clarified its timing in relation to each trimester (we were studying cases with first trimester abortion only) Also, the patient was asked if any investigations were done to identify the cause of miscarriage.

Examination: general and abdominal examinations were done. Investigations: liver enzymes, bilirubin (total and direct), serum creatinine, urine analysis, TSH, fasting and $2 \mathrm{hr}$ postprandial blood sugar were done along with screening for APAS and SLE and 3D transvaginal U/S, all should be normal.

Method of FVL screening: The screening was done by functional APCR testing. This test identifies patients who have APCR, depending on the fact that more than $95 \%$ of cases of APCR are due to FVL mutation ${ }^{[7]}$.

This test depends on the fact that in cases of APCR; there is a reduced anticoagulant response of patient plasma after adding a standard amount of APC. So in this assay, the aPTT clotting test fails to prolong significantly after the addition of APC, indicates resistance ${ }^{[7]}$.

Reagent preparation: The reagent was provided in a vial containing approximately 10 microgram of APC, freeze dried (Purified APC, Cat no \#00828, Diagnostica Stago, France).

The APC reagent was reconstituted with $1 \mathrm{ml}$ of distilled water, then $0.025 \mathrm{M} \mathrm{CaCl} 2$ was used to prepare a 1:10 dilution of the reconstituted reagent to obtain a final APC concentration of approximately 1 microgram $/ \mathrm{ml}$. A carefully standardized amount of APC was used for testing.

Procedure: The APC test was performed on anti-coagulated blood. The APTT values obtained with patient plasma with and without adding APC must be compared with the corresponding APTT values of reference plasma (being made up of about 10 normal plasma tested alone or as a pool). 
Ratio Value: First, calculate the sensitivity ratio to APC (APC-SR) of the patient plasma. This ratio is represented by:

$$
\text { APC-SR }=\frac{\text { Clotting time of tube } 2}{\text { Clotting time of tube } 1}
$$

Similarly, calculate the APC-SR of the reference plasma. Then, the normalized ratio (n-APC-SR) of the test plasma is:

$$
\mathrm{n} \text {-APC-SR }=\frac{\text { APC-SR of patient plasma }}{\text { APC-SR of reference plasma }}
$$

Our laboratory cut-off was 0.82 to obtain the best sensitivity and specificity. Where n-APC-SR $<0.82$, indicate APC resistance.

The high sensitivity and specificity of the APC ratio (approaching 100\%) together with its reliability and ease with which it is performed, make it an adequate screening method ${ }^{[8]}$.

Patients who test positive by a functional assay should

\begin{tabular}{|c|c|c|}
\hline In a test tube at $37^{\circ} \mathrm{C}$ & Tube (1) & Tube (2) \\
\hline $\begin{array}{l}\text {-Plasma (patient } \\
\text { or reference) }\end{array}$ & $100 \mu 1$ & $100 \mu 1$ \\
\hline •PTT & $100 \mu 1$ & $100 \mu 1$ \\
\hline -Mix,incubate & $3 \mathrm{~min}$ & \\
\hline $\begin{array}{l}\text {-Starting a stop-watch, } \\
\text { add } 0.025 \mathrm{M} \mathrm{CaCl} 2 \\
\text { prewared at } 37^{\circ} \mathrm{C}\end{array}$ & $100 \mu 1$ & \\
\hline $\begin{array}{l}\text {-Starting a stop- } \\
\text { watch,add diluted APC } \\
\text { prewarmed at } 37^{\circ} \mathrm{C}\end{array}$ & & $100 \mu \mathrm{l}$ \\
\hline
\end{tabular}
then be further studied with DNA test for confirmation and to distinguish heterozygotes from homozygotes. However, this is beyond our study.

Mix and note the clotting time of each tube

\section{STATISTICAL ANALYSIS:}

Data were statistically described in terms of mean \pm standard deviation $( \pm \mathrm{SD})$, median and range or frequencies (number of cases) and percentages when appropriate. Comparison of numerical variables between the study groups was done using Student t test for independent samples in comparing the 2 groups when normally distributed and Mann Whitney U test for independent samples when not normally distributed.
For comparing categorical data, Chi square $(\div 2)$ test was performed. Exact test was used instead when the expected frequency is less than 5. P values less than 0.05 was considered statistically significant. All statistical calculations were done using computer program SPSS ${ }^{[9]}$.

\section{RESULTS}

We analyzed both groups concerned with many variables including demographic data, obstetric history and prevalence of APCR (FVL screening test).

\section{Demographic data and obstetric history:}

In our study, statistical studies between our case and control groups showed no significant differences as regards maternal age.

In spite of that, significant differences were detected as regard to number of successful pregnancies and number of abortions $(P$ value $<0.05)$ with no significant difference regarding gestational age at abortion, as shown in Table 1.

In respect to the mean number of successful pregnancies (pregnancies reaching 36 completed gestational weeks or more) in each group, it was $2.42( \pm 0.66)$ (occurring in $100 \%$ of women) varying between 1 and 4 pregnancies of a total of 201 successful pregnancies in our control group, while the mean number in the case group in women who had previous pregnancies was $0.31( \pm 0.59)$ (occurring in 20 out of 83 ) varying between 1 and 2 pregnancies at maximum, then followed by history of RPL.

As regarding number of abortion in our control group, only 25 women had abortion (23 of them only once and 2 women had abortion twice, but not consecutive). While in our case group, the total number of abortion is 298 abortion as all the patient had at least 3 consecutive abortion, some had 4 consecutive abortion and other had 5 with the fact that one woman had 13 consecutive abortion. All abortions took place in the $1^{\text {st }}$ trimester. Data was statistically significant as regard to number of abortion but not statistically significant in relation to gestational week of abortion (Table1).

APCR test results: Abnormal APCR test values were found in a total of 22 women in our study, 7 women in the control group and 15 in the case group.

No statistically significant differences were recognized between both groups related to APCR test values (with $P$ value $=0.2859$ ) as shown in Table 2 .

We then divide the case groups into further two groups, the first with normal APCR test and the other with abnormal test result to allow further studying of the impact of abnormal test on the pregnancy outcome. 


\section{The RPL (case) group observation:}

Analysis of the data obtained from the case group revealed that a total of 68 patients $(82 \%)$ had a normal APC resistance test value (above 0.82 ), while only 15 patients (18\%) showed abnormal values (below 0.82).

Demographic data recognized no statistically significant differences regarding the age, number of abortions, gestational weeks at abortion and number of successful pregnancies, while significant difference was found as regards APC resistance test values as shown in Table 3.

Regarding DVT incidence, only two patients in the case group with abnormal APC value suffered from DVT episodes representing $13.3 \%$ of 15 patient with abnormal APCR in our case group. The $P$ value is statistically significant which mean that the present of APCR might increase the risk for DVT (Table 4).

Table 1: Comparison between both groups as regards the mean values of age, number of successful pregnancies, number of abortions and average gestational age at abortion, and their statistical significance

\begin{tabular}{|c|c|c|c|c|c|}
\hline Variables & Control group $(\mathrm{n}=83)$ & $\begin{array}{l}\text { Case group } \\
(\mathrm{n}=83)\end{array}$ & Difference & $95 \% \mathrm{CI}$ & Pvalue \\
\hline Age ( years) & $28.4( \pm 4.17)$ & $27.8( \pm 4.7)$ & -0.600 & $\begin{array}{l}1.9518 \text { to } \\
0.7518\end{array}$ & $0.3821(\mathrm{NS})$ \\
\hline $\begin{array}{l}\text { Number of successful } \\
\text { pregnancies }\end{array}$ & $\begin{array}{c}2.42( \pm 0.66) \\
\text { (of total } 201 \text { successful } \\
\text { pregnancies) }\end{array}$ & $\begin{array}{c}0.31( \pm 0.59) \\
\text { (of total } 26 \text { successful } \\
\text { pregnancies) }\end{array}$ & -2.110 & $\begin{array}{c}-2.3019 \text { to } \\
-1.9181\end{array}$ & $<0.0001(\mathrm{~S})$ \\
\hline Number of abortions & $0.32( \pm 0.517)$ & $\begin{array}{c}3.59( \pm 1.55) \\
\text { (minimum: } 3 \text {, maximum: 13) }\end{array}$ & 3.270 & $\begin{array}{c}2.9159 \text { to } \\
3.6241\end{array}$ & $<0.0001(\mathrm{~S})$ \\
\hline $\begin{array}{l}\text { Gestational age at } \\
\text { abortions (weeks) }\end{array}$ & $\begin{array}{c}8.5( \pm 2.6) \\
\text { (of total of } 27 \text { abortions) }\end{array}$ & $\begin{array}{c}8.4( \pm 1.4) \\
\text { (of total of } 298 \text { abortions) }\end{array}$ & -0.100 & $\begin{array}{c}-0.7057 \text { to } \\
0.5057\end{array}$ & $0.7455(\mathrm{NS})$ \\
\hline
\end{tabular}

Data are presented as Mean $( \pm \mathrm{SD})$.

$\mathrm{n}=$ number, $\mathrm{NS}=$ not significant, $\mathrm{S}=$ significant, $95 \% \mathrm{CI}=95 \%$ confidence interval.

Table 2: Comparison between both groups regarding the Number of patients with abnormal APC ratio and APC ratio values, and their statistical significance

\begin{tabular}{lccccc}
\hline Variables & Control group $(\mathrm{n}=83)$ & Case group $(\mathrm{n}=83)$ & Difference & $95 \%$ CI & $P$ value \\
\hline $\begin{array}{l}\text { Number of patients with } \\
\text { abnormal APC resistance test }\end{array}$ & $7(8.43 \%)$ & $15(18.07 \%)$ & $9.64 \%$ & -0.8344 to $20.1787 \%$ & 0.0678 (NS) \\
APC resistance test value & $0.846( \pm 0.050)$ & $0.837( \pm 0.058)$ & -0.009 & -0.0256 to 0.0076 & 0.2859 (NS) \\
\hline
\end{tabular}

Data are presented as Mean $( \pm \mathrm{SD})$.

$\mathrm{n}=$ number, $\mathrm{NS}=$ not significant, $\mathrm{S}=$ significant, $95 \% \mathrm{CI}=95 \%$ confidence interval. 
Table 3: Comparison as regard age, number of abortions, average gestational weeks at abortion, number of successful pregnancies and APC resistance test value (in case group)

\begin{tabular}{|c|c|c|c|c|c|}
\hline Variables & $\begin{array}{c}\text { Normal APC resistance } \\
\text { test }(\mathrm{n}=68)\end{array}$ & $\begin{array}{l}\text { Abnormal APC } \\
\text { resistance test }(n=15)\end{array}$ & Difference & $95 \% \mathrm{CI}$ & Pvalue \\
\hline Age (years) & $26.42( \pm 5.42)$ & $28.26( \pm 3.73)$ & 1.840 & 1.0930 to 4.7730 & $0.2155(\mathrm{NS})$ \\
\hline Number of abortions & $4.1( \pm 1.35)$ & $4.6( \pm 1.5)$ & 0.500 & -0.2816 to 1.2816 & $0.2067(\mathrm{NS})$ \\
\hline $\begin{array}{l}\text { Average gestational } \\
\text { week at abortion }\end{array}$ & $8.45( \pm 1.10)$ & $7.86( \pm 1.30)$ & -0.590 & -1.2354 to 0.0554 & $0.0726(\mathrm{NS})$ \\
\hline $\begin{array}{l}\text { APC resistance } \\
\text { test value }\end{array}$ & $0.86( \pm 0.029)$ & $0.72( \pm 0.027)$ & -0.140 & -0.1563 to -0.1237 & $<0.0001(\mathrm{~S})$ \\
\hline
\end{tabular}

Data are presented as Mean $( \pm \mathrm{SD})$.

$\mathrm{APC}=$ Activated protein $\mathrm{C}, \mathrm{n}=$ number, $\mathrm{NS}=$ not significant, $\mathrm{S}=$ significant, $\mathrm{CI}=\mathrm{Confidence}$ Interval.

Table 4: Comparison between incidences of DVT

\begin{tabular}{|c|c|c|c|c|c|}
\hline Variables & $\begin{array}{c}\text { Normal APC resistance } \\
\text { test }(\mathrm{n}=68)\end{array}$ & $\begin{array}{l}\text { Abnormal APC } \\
\text { resistance test }(n=15)\end{array}$ & Difference & $95 \% \mathrm{CI}$ & $P$ Value \\
\hline DVT & $0(0 \%)$ & $2(13.3 \%)$ & $13.3 \%$ & $\begin{array}{c}2.3298 \% \text { to } \\
37.8438 \%\end{array}$ & $0.0025(\mathrm{~S})$ \\
\hline
\end{tabular}

Data are presented as Mean $( \pm \mathrm{SD})$.

$\mathrm{n}=$ number, $\mathrm{NS}=$ not significant, $\mathrm{S}=$ significant, $95 \% \mathrm{CI}=95 \%$ confidence interval.

\section{DISCUSSION}

In recurrent pregnancy loss, there is much debate about cause and association. One of those debates include inherited thrombophilia and its prevalence among women with history of recurrent pregnancy loss. This was one of the important causes that motivated us to perform this study.

In our case-control study, we compared the prevalence of APCR among 83 patients in the case group, with history of 3 or more unexplained first trimesteric pregnancy losses, after exclusion of the most important well established causes of RPL including APAS and anatomic uterine anomalies (by normal laboratory investigations and 3D US) with 83 fertile women in the control group who have not experienced RPL. The aim of this study was to investigate the prevalence of one of the genetic abnormalities frequently associated with venous thrombosis (FVL), which is responsible for about $95 \%$ of cases of APCR, in patients with unexplained first trimesteric RPL.
Regarding the demographic data as seen in Table 1, there was no statistically significant difference between both groups as regards age of women included, with mean age of 28.4 and 27.8 years in the control and case groups, respectively, which is considered important to exclude the effect of age on the results. It is to be stated that all studies done to assess the relationship between thrombophilias and RPL included women around this age group (30's) with no statistically significant differences between their case and control groups.

As regards the obstetric history, table 1 showed that there is a statistically significant difference between both groups in the number of successful pregnancies (ending in live births). As we see, the number of successful pregnancies is significantly higher in the control group with $P$ values $<0.0001$.

There was statistically significant difference between the two groups regarding the number of abortion $(P$ value $=<0.0001)$ but no statistically significant was proven as regard to the mean gestational week at abortions as can be noted by reviewing table 1 
with 8.5 weeks in the control group and 8.4 weeks in the case group.

It should be noted that abortion happened in either second or third trimester had been excluded out of our study from the beginning and substituted by $1^{\text {st }}$ trimesteric abortion.

Table 2 showed the difference between case and control groups regarding the number of patients with abnormal APC resistance test and APC resistance test value. Although the number of patients with abnormal APC resistance test results $(<0.82)$ was higher in the case group (15 out of 83 with $18.07 \%$ prevalence) than in the control group ( 7 out of 83 with $8.43 \%$ prevalence), while the mean test values were higher with the control group (0.846) than with the case group (0.837), however, none of these parameters showed any statistically significant difference. However, the relatively higher incidence of abnormal APCR test results in the case group suggested that it may have a role in first trimesteric RPL.

These results agree with the study done by Reddy $\mathrm{RRN}^{[10]}$ where evaluation of 78 pregnant women for FVL mutation revealed that only $1(2 \%)$ was positive for heterozygous with odds ratio 1.72 (95\% confidence interval, 0.0681-43.8257; $P>0.05)$. The result was statistically non-significant concluding that FVL investigation may not be included in the battery of tests for recurrent miscarriage in Indian population.

Another study performed by Teremmahi Ardestani et $a l^{[11]}$. could not demonstrate any clear association between RPL (defined as 2 or more unexplained first trimester pregnancy losses) with hereditary APCR. Unlike ours, they performed the DNA analysis for identification of FVL genotype. Regarding the results, two patient with first-trimester repeated abortion (2.5\%) and one control subject (1.25\%) had Factor V Leiden mutation. Genotype analysis confirmed that both subjects were heterozygous for FVL and they concluded that first-trimester repeated abortion is not associated with APCR and that FVL screening in first-trimester repeated abortion is not warranted.

Also, our results agree with another study done to elucidate the relationship between inherited thrombophilia and RPL in Colombian couples conducted by Cardona Henry et $a l^{[12]}$. where they defined RPL as 3 or more first trimesteric pregnancy losses and they also included any of the following vascular pregnancy manifestations: one or more second-trimester or later losses, severe or recurrent preeclampsia, intrauterine growth restriction, placental abruption, or otherwise unexplained intrauterine death. They assessed FVL by both APCR test and DNA analysis.
FVL is generally $3-5 \%$ of the Caucasian population in Europe and USA ${ }^{[13]}$. In contrast, its prevalence is $<1 \%$ in south-east Asia, the Middle East and Africa $^{[13]}$.

Our results coincide also with many studies done in different countries as that done in Germany by Pauer et al. ${ }^{[14]}$ (who included cases with 2 or more pregnancy losses, with FVL prevalence in case group; $11 / 101$ vs. $9 / 122$ in the control group, with p-value: 0.348), in France done by Pasquier et al. ${ }^{[15]}$ where the prevalence of female, male or couple thrombophilic mutations was not statistically different between cases and controls and another study done in Netherlands by Coppens et al. ${ }^{[16]}$ where they assessed the pregnancy outcome of the second pregnancy after a first loss in women with and without either FVL or P.m. mutations; the live birth rate of the second pregnancy after an early first loss $(<$ or $=12$ weeks of gestation) was $77 \%$ (95\% CI 62-87) for carriers and $76 \%$ (95\% CI 57-89) for non-carriers

In contrast, many studies didn't agree with our study ${ }^{[17-22]}$. However, the accuracy of these studies may be limited by the variation between studies in many items including the definition of RPL, the number of women involved, the inclusion and exclusion criteria and the thrombophilias to be examined. For example, regarding the definition of RPL, unlike our study, some studies defined it as 2 or more pregnancy losses as those done by Finan et al. ${ }^{[17]}$, Foka et al. ${ }^{[20]}$ and Younis et al. ${ }^{[22]}$ which can be a cause of the different results. Also, the main drawback of some studies was that they included pregnancy loss in general so didn't differentiate between first trimesteric and late recurrent pregnancy losses which may affect the results also as in Foka et al. ${ }^{[20]}$ and Wramsby et al. ${ }^{[21]}$.

A recent meta-analysis done by Rodger et al. ${ }^{[23]}$ found that the OR of pregnancy loss in women with FVL appears to be $52 \%$ higher as compared with women without FVL, however these results are influenced by statistical and clinical heterogeneity in the analysis. Overall the absolute event rate for pregnancy loss is low $(4.2 \%)$ and only appears slightly higher than the rate of pregnancy loss in women without FVL (3.2\%).

For further identification of the effect of APCR on pregnancy outcome, we further divided the case group into 2 subgroups including women with normal and abnormal APC resistance results.

Of the 83 women in the case group who were included in our study, all had a clinically recognized pregnancy at least once. Only 15 of them (18\%) showed abnormal APCR test, while 68 (82\%) had normal results as seen in table 3. Only the value of APCR test was statistically significant $(P$ value $<0.0001)$ as shown in table 3 . 
It is to be noted that two of patients who had abnormal results gave a history of 9 and 7 abortions; all were first trimesteric, each had an episode of DVT. Our comparison study in case group had shown that there might be increase risk of DVT in patient with APCR result, which is statistically significant $(P$ value $=0.0025)$ as shown in table 4 .

That result goes along with study done by Elgari et $a{ }^{[24]}$ revealing that frequency and prevalence of heterozgygous FVL mutation among Saudian females with history of DVT was $7(11.6 \%)$ which was statistically significant.

As many studies, including those that found a significant association between FVL mutation and RPL, have marked that some women who have the FVL allele had uncomplicated pregnancies, and they had concluded also that maternal carriage of this thrombophilic mutation did not interfere with a successful, uncomplicated live birth at term so they reach to final conclusion that not all women who carry a thrombophilic mutation suffer a pregnancy loss and perhaps it is those who carry multiple thrombophilic defects who are at greatest risk ${ }^{[25,26]}$.

From all the previously stated studies, it is very noticeable that there is a huge contradiction in their results, which may partially explained by selection bias as the small numbers of women that have been observed in some studies or by genetic polymorphism, bias in patient selection, or ethnic heterogeneity within the patients studied.

\section{CONCLUSION}

In this study, it was concluded that isolated factor $\mathrm{V}$ Leiden may increase the risk of RPL. However, it is unlikely to be an important cause as no statistically significant difference in the incidence of RPL was found between the case and control groups.

\section{CONFLICT OF INTEREST}

There are no conflicts of interests.

\section{REFERENCES}

1. Kagami M, Maruyama T, Koizumi T, Miyazaki $\mathrm{K}$, Nishikawa-Uchida $\mathrm{S}$, Oda $\mathrm{H}$, Uchida $\mathrm{H}$, Fujisawa D, Ozawa N, Schmidt L, Yoshimura Y. Psychological adjustment and psychosocial stress among Japanese couples with a history of recurrent pregnancy loss, Human Reproduction, Volume 27, Issue 3, March 2012.
2. El Hachem H, Crepaux V, May-Panloup P, Descamps P, Legendre G, Bouet PE. Recurrent pregnancy loss: current perspectives. Int J Womens Health. 2017; 9: 331-345.

3. Abu-Heija A. Thrombophilia and Recurrent Pregnancy Loss: Is heparin still the drug of choice. Sultan Qaboos Univ Med J. 2014;14(1):e26-e36.

4. Ormesher L, Simcox L, Tower C, Greer IA. Management of inherited thrombophilia in pregnancy. Womens Health (Lond). 2016;12(4):433-441.

5. Kadauke, S. , Khor, B. and Van, Cott, E. M. , Activated protein $\mathrm{C}$ resistance testing for factor $\mathrm{V}$ Leiden. Am. J. Hematol., 89: 1147-1150, 2014.

6. Yusuf M, Gupta A, Kumar A, Afreen S. Mechanism and pathophysiology of activated protein C-related factor $\mathrm{V}$ leiden in venous thrombosis. Asian $\mathrm{J}$ Transfus Sci. 2012;6(1):47-48.

7. Elizabeth M. Van Cott, Britt L. Soderberg, and Michael Laposata Activated Protein C Resistance, the Factor V Leiden Mutation, and a Laboratory Testing Algorithm. Archives of Pathology \& Laboratory Medicine: May 2002, Vol. 126, No. 5 , pp. $577-582$

8. Bertina, R., Koeleman, B., Koster, T. et al. Mutation in blood coagulation factor $\mathrm{V}$ associated with resistance to activated protein C. Nature 369, 64-67 (1994).

9. Statistical Package for the Social Science; SPSS Inc., Chicago, IL, United states of America (USA) release 15 for Microsoft Windows (2006).

10. Reddy RRN, Mutreja D, Moorchung N, Mukhopadhyay I. Recurrent pregnancy loss: can factor V Leiden mutations be a cause. Obstet Gynecol Sci. 2019;62(3):179-182.

11. Teremmahi Ardestani, Majid et al. Case control study of the factor V Leiden and factor II G20210A mutation frequency in women with recurrent pregnancy loss. Iranian journal of reproductive medicine, 2013, 11.1: 61 .

12. Cardona H, Castañeda SA, Cardona Maya W, et al. Lack of Association between Recurrent Pregnancy Loss and Inherited Thrombophilia in a 
Group of Colombian Patients. Thrombosis. 2012; 2012:367823.

13. Rees DC, Cox M and Clegg JB. world distribution of factor V Leiden. Lancet; 1995; 346, 1133-1134.

14. Pauer HU, Vogt TT, Hinney B. Analyzes of three common thrombophilic gene mutations in German women with recurrent abortions. Acta Obst Gynecol Scand; 2003; 82: 942-7.

15. Pasquier E, Bohec C, Mottier D, Jaffuel S, Mercier B, Férec C, Collet M, De Saint Martin L. Inherited thrombophilias and unexplained pregnancy loss: an incident case-control study. J Thromb Haemost; 2009; 7: 306-11.

16. Coppens M, Folkeringa N, Teune MJ, Hamulyák K, van der Meer J, Prins MH, Büller HR, Middeldorp $\mathrm{S}$. Outcome of the subsequent pregnancy after a first loss in women with the factor $\mathrm{V}$ Leiden or prothrombin 20210A mutations. J Thromb Haemost. 2007; 5:1444-8.

17. Finan RR, Tamim H, Ameen G, Sharida HE, Rashid M, Almawi WY. Prevalence of factor V G1691A (factor V-Leiden) and prothrombin G20210A gene mutations in a recurrent miscarriage population. Am J Hematol 2002, 71:300-305.

18. Sarig G, Younis J, Hoffman R, et al. Thrombophilia is common in women with idiopathic pregnancy loss and is associated with late pregnancy wastage. Fertil Steril. 2002; 77:342-347.

19. Reznikoff-Etievan MF, Cayol V, Carbonne B, Robert A, Coulet F \& Milliez J. Factor V Leiden and G20210A prothrombin mutations are risk factors for very early recurrent miscarriage. British Journal of Obstetrics and Gynaecology, 2001; 108, 1251-1254.
20. Foka ZJ, Lambropoulos AF, Saravelos H, Karas GB, Karavida A, Agorastos T, Zournatzi V, Makris PE, Bontis J, Kotsis A. Factor V leiden and prothrombin G20210A mutations, but not methylenetetrahydrofolate reductase C677T, are associated with recurrent miscarriages. Hum Reprod 2000, 15:458-462.

21. Wramsby ML, Sten-Linder M, Bremme K. Primary habitual abortions are associated with high frequency of factor V Leiden mutation. Fertil Steril. 2000;74:987-991.

22. Younis JS, Ohel G, Brenner B, Haddad S, Lanir $\mathrm{N}$, Ben-Ami M. The effect of thrombophylaxis on pregnancy outcome in patients with recurrent pregnancy loss associated with factor V Leiden mutation. BJOG; 2000, 107:415-419

23. Rodger MA, Betancourt MT, Clark P, Lindqvist PG, Dizon-Townson D, et al. The Association of Factor V Leiden and Prothrombin Gene Mutation and Placenta-Mediated Pregnancy Complications: A Systematic Review and Metaanalysis of Prospective Cohort Studies. PLOS Medicine, 2010; 7(6): e1000292.

24. Mahmoud Mohamed Elgari, Nadir Ahmed Ibrahim, Abdel Rahim Mahmoud Muddathir, Faris Mergheni Eltoom, and Ibrahim M Ibrahim. "Frequency of Thrombophilic Gene Mutations in Patients with Deep Vein Thrombosis and in Women with Recurrent Pregnancy Loss" Open Life Sciences, vol. 12, no. 1, 2017.

25. Preston F, Rosendaal F, Walker I, Brient E, Berntorp E, Canard J, Fontcuberta J, Markris. Increased fetal loss in women with heritable thrombophilia. Lancet; 1996; 348:913-916.

26. Rai R, Backos M, Elgaddal S, Shlebak A, Regan L. Factor V Leiden and recurrent miscarriageprospective outcome of untreated pregnancies. Hum Reprod; 2002; 17:442-5. 